\title{
A Water Dispersible Nanocomposite of Polyacrylonitrile with Silica via Aqueous Polymerization of Acrylonitrile by $\mathrm{K}_{2} \mathrm{CrO}_{4}-\mathrm{NaAsO}_{2}$ Redox System
}

\author{
Arjun MAITY and Mukul BISWAS ${ }^{\dagger}$ \\ Department of Chemistry, Presidency College,Calcutta-73, West Bengal, India
}

(Received August 1, 2003; Accepted September 8, 2003)

\begin{abstract}
The aqueous polymerization of acrylonitrile initiated by the redox pair, potassium chromate-sodium arsenite produced polyacrylonitrile which was recovered as a coagulum in the medium. A simple procedure was developed for obtaining a stable suspension of polyacrylonitrile- $\mathrm{SiO}_{2}$ nanocomposite by conducting the polymerization in presence of $\mathrm{SiO}_{2}$ as a particulate dispersant. SEM analyses revealed distinct morphological features of the polyacrylonitrile-SiO${ }_{2}$ nanocomposite. TEM analyses indicated the particle sizes of the polyacrylonitrile- $\mathrm{SiO}_{2}$ composite to be in the $28-100 \mathrm{~nm}$ range. TG analyses revealed the enhanced thermal stability of the polyacrylonitrile- $\mathrm{SiO}_{2}$ nanocomposite relative to that of the base polymer polyacrylonitrile. The d.c. conductivities of the polyacrylonitrile- $\mathrm{SiO}_{2}$ and polyacrylonitrile- $\mathrm{SiO}_{2}$ ( $\mathrm{FeCl}_{3}$ doped) composites were in the order of $10^{-6} \mathrm{~S} \mathrm{~cm}^{-1}$ and $10^{-5} \mathrm{~S} \mathrm{~cm}^{-1}$ respectively.

KEY WORDS Homopolymerization / Polyacrylonitrile / Redox / Nanocomposite / Colloidal Silica / Water Dispersibility / Conductivity /
\end{abstract}

A vast literature exists on the preparation and evaluation of processible nanocomposites of intractable polymers like polyaniline (PANI), ${ }^{1}$ polypyrrole (PPY) ${ }^{2}$ polythiophene (PTP), ${ }^{3}$ poly- $N$-vinylcarbazole $(\mathrm{PNVC}),{ }^{4}$ and binary combinations ${ }^{5}$ thereof with montmorillonite (MMT)-clay, ${ }^{1-4}$ nanometal oxides such as $\mathrm{Al}_{2} \mathrm{O}_{3},{ }^{6-8} \mathrm{ZrO}_{2},{ }^{9} \mathrm{MnO}_{2},{ }^{10} \mathrm{SiO}_{2}$, and $\mathrm{SnO}_{2}{ }^{11-19}$ as particulate dispersants. The procedure generally adopted was to add pyrrole (PY) or aniline (ANI) to an aqueous dispersion of the nanodimensional metal oxides in presence of oxidants such as $\mathrm{FeCl}_{3}$ or $\left(\mathrm{NH}_{4}\right)_{2} \mathrm{~S}_{2} \mathrm{O}_{8}$. For water-insoluble monomers like $\mathrm{N}$-vinylcarbazole (NVC) or thiophene (TP), Biswas et $a .^{20}$ developed a suspension polymerization technique using combination of water and appropriate nonaqueous solvents (for the monomers) in presence of usual oxidants to produce the corresponding nanocomposites.

A significant recent development in this direction was the application of emulsion polymerization technique by Choi et al. ${ }^{21-24}$ for the formation of nanocomposites of both speciality polymers (PANI, PPY) and the fundamental polymers (polystyrene, polyacrylonitrile, and copolymers thereof) with $\mathrm{Na}^{+}$-MMT clay. Inverted emulsion pathway was recently described by Choi et $a l .{ }^{25}$ for the preparation of intercalated PPY $/ \mathrm{Na}^{+}$-MMT nanocomposite.

In the above background, we wish to report in this article a simple procedure of preparing a $\mathrm{PAN}-\mathrm{SiO}_{2}$ nanocomposite via aqueous polymerization of $\mathrm{AN}$ by $\mathrm{Cr}^{6+} / \mathrm{AsO}_{2}{ }^{-}$redox pair in presence of nanodimensional silica as particulate dispersants. The scope of this procedure is fairly wide since a variety of acrylic monomers and combinations thereof may be employed in presence of suitable particulate dispersants for the fabrication of the respective nanocomposites. We shall also describe some relevant bulk properties such as morphology, thermal stability, conductivity, and water dispersibility of the $\mathrm{PAN}_{-} \mathrm{SiO}_{2}$ nanocomposite.

\section{EXPERIMENTAL}

\section{Materials and Methods}

Acrylonitrile (Aldrich, USA) was freed from inhibitors by successive washings with dilute sodium carbonate solution, dilute sulfuric acid and finally with distilled water. It was kept over-night over calcium chloride and distilled in an all glass apparatus. The fraction boiling at $77-78^{\circ} \mathrm{C}$ was collected and stored carefully. Potassium chromate (Riedel, Germany) and sodium arsenite (Riedel, Germany) were used as the oxidant and the reductant respectively. SM-30 Colloidal ( $30 \%$ weight suspension in water, density $1.22 \mathrm{~g} \mathrm{~mL}^{-1}$ ) $\mathrm{SiO}_{2}$ (Aldrich, USA) was used as the particulate dispersant. All other solvents were of analytical grade and were freshly distilled before used.

\section{Polymerization of Acrylonitrile with $\mathrm{K}_{2} \mathrm{CrO}_{4}-\mathrm{NaAsO}_{2}$} Redox System

In a Pyrex flask, a definite amount (1.8$3.0 \times 10^{-3} \mathrm{~mol}$ ) of $\mathrm{K}_{2} \mathrm{CrO}_{4}$ was dissolved in $30 \mathrm{~mL}$ distilled water to which $0.02 \mathrm{~mol}$ of acrylonitrile was injected. The system was kept under stirring at ambient temperature under $\mathrm{N}_{2}$ atmosphere for $10 \mathrm{~min}$ and there- 
after, a definite amount $\left(3.8 \times 10^{-4}-2.3 \times 10^{-3} \mathrm{~mol}\right)$ of $\mathrm{NaAsO}_{2}$ was dissolved into this solution. The induction periods were within 3-5 min and the polymerization was allowed to continue for 2-6h. Thereafter, the white polymer was centrifuged, washed in succession with distilled water, methanol, and acetone and finally dried in vacuum for $12 \mathrm{~h}$. Conversions were estimated gravimetrically.

\section{Preparation of $\mathrm{PAN}-\mathrm{SiO}_{2}$ Nanocomposite}

$0.1-0.5 \mathrm{~g}$ of silica was added to $30 \mathrm{~mL}$ of distilled water taken in a $50 \mathrm{~mL}$ Pyrex flask under sonication in which a definite amount $\left(1.8-3.0 \times 10^{-3} \mathrm{~mol}\right)$ of $\mathrm{K}_{2} \mathrm{CrO}_{4}$ was dissolved and $0.02 \mathrm{~mol}$ of acrylonitrile monomer was injected. The system was kept under stirring at ambient temperature under $\mathrm{N}_{2}$ atmosphere for $10 \mathrm{~min}$. Thereafter, a definite amount $\left(3.8 \times 10^{-4}\right.$ $2.3 \times 10^{-3} \mathrm{~mol}$ ) of $\mathrm{NaAsO}_{2}$ was added to it. The system was allowed to polymerize for a definite time period. The white suspension was centrifuged and the separated mass was washed in succession with distilled water, methanol and acetone and finally dried in vacuum for $12 \mathrm{~h}$.

\section{Chacterization and Property Evaluation of PAN and $\mathrm{PAN}-\mathrm{SiO}_{2}$ Nanocomposite}

Intrinsic viscosity of PAN homopolymer was determined with in Ostwald viscometer in dimethylformamide (DMF) solution at $25^{\circ} \mathrm{C}$ and molecular weight was calculated using the Ueberreiter-Springer equation, $[\eta]=16.6 \times 10^{-5} \times \mathrm{M}^{0.81}{ }^{26,27}$ The Fourier transform infrared (FT-IR) spectra of PAN and $\mathrm{PAN}_{-} \mathrm{SiO}_{2}$ composite were taken on a JASCO-410 instrument (Essex, UK) in pressed $\mathrm{KBr}$ pellets. Dispersion of $\mathrm{PAN}-\mathrm{SiO}_{2}$ nanocomposite in 2-Propanol was microsprayed on a mica substrate. The sample was sputter coated with gold layer and a Hitachi S-415A (Tokyo, Japan) scanning electron micrograph was used to take the micrograph. The particle sizes of the $\mathrm{PAN}-\mathrm{SiO}_{2}$ composites were measured by a Hitachi H-600 transmission electron microscope (Tokyo, Japan), with diluted suspension $(1000 \mathrm{ppm})$ in 2-Propanol on the copper grid. Thermogravimetric analyses were performed on a Shimadzu DT-40 (Kyoto, Japan) instrument.

\section{RESULTS AND DISCUSSION}

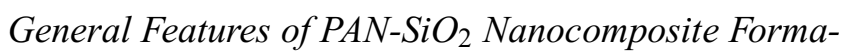 tion}

The aqueous polymerization of AN could not be induced by $\mathrm{Cr}^{6+}$ or $\mathrm{AsO}_{2}{ }^{-}$alone under ambient and higher temperature conditions. Polymerization occurred only when both the constituents were present in

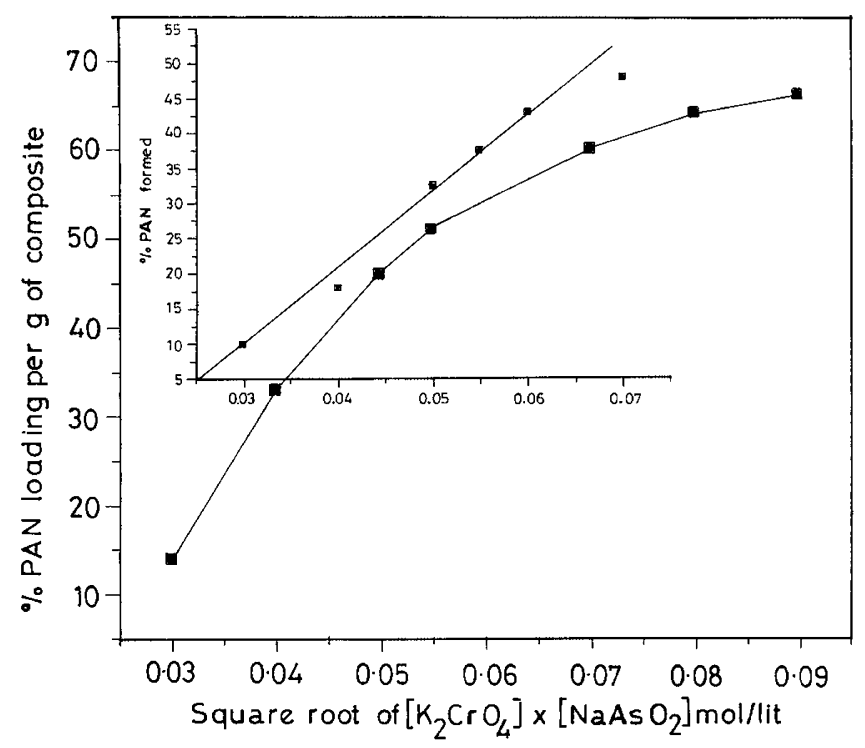

Figure 1. Dependence of \% PAN loading per $\mathrm{g}$ of composite and of \% PAN homopolymerization (inset) on the $\sqrt{\left[\mathrm{K}_{2} \mathrm{CrO}_{4}\right]}$ $\left[\mathrm{NaAsO}_{2}\right] \mathrm{mol} \mathrm{L}^{-1} ;[\mathrm{AN}]=0.75 \mathrm{~mol} \mathrm{~L}^{-1}$.

the reaction mixture.

With the recipe used in the present study the polymerizations were pretty fast and after an induction period varying from 3-5 min, the appearance of a milky white suspension of polymer PAN could be noted. At the end of the polymerization time the suspension coagulated in the medium which was centrifuged and the $\%$ conversion was determined gravimetrically. PAN homopolymer thus collected was characterized by FT-IR spectroscopy. The molecular weight of the polymer as determined viscometrically was $7.9 \times 10^{4} \mathrm{~g} \mathrm{~mol}^{-1}$.

In presence of nanodimensional $\mathrm{SiO}_{2}$ dispersed in the water medium the polymerization of AN occurred with comparable speed as in the homopolymerization system. In this case a PAN suspension was obtained which was centrifuged at $15000 \mathrm{rpm}$ to estimate the solid content. PAN content in this $\mathrm{PAN}-\mathrm{SiO}_{2}$ composite thus obtained was determined by subtracting the weight of $\mathrm{SiO}_{2}$ in the initial feed from the total weight of PAN-SiO 2 composite. The FT-IR scan for PAN-SiO composite revealed the manifestation of peaks $\left(\mathrm{cm}^{-1}\right)$ at 2939 (C-H stretching), 2250 (C $\equiv \mathrm{N}$ stretching) and 1454 (C-H bending) which matched with the reported FT-IR spectra for PAN. ${ }^{28-30}$

Figure 1 shows that \% PAN loading per g of composite increased with the square root of the product of $\left[\mathrm{K}_{2} \mathrm{CrO}_{4}\right]$ and $\left[\mathrm{NaAsO}_{2}\right]$ at fixed amount of $\mathrm{SiO}_{2}$ in the initial feed. This trend would be expected since the overall yield of PAN (inset of Figure 1) and hence its $\%$ loading in the composite with fixed $\mathrm{SiO}_{2}$ was found to increase with an increase in the product of $\left[\mathrm{K}_{2} \mathrm{CrO}_{4}\right]$ and $\left[\mathrm{NaAsO}_{2}\right]$.

Figure 2 shows that \% PAN loading per $g$ of compos- 
ite increased progressively to a limiting value with the time of the polymerization at fixed initial feed composition of the polymerization. This trend was parallel to the variation of the $\%$ conversion to PAN with time.

\section{Scanning Electron Microscopic Analysis}

Several scanning electron micrographic images of the $\mathrm{PAN}-\mathrm{SiO}_{2}$ nanocomposite are presented in Figure 3 (a)-3 (d) which clearly revealed that the PAN$\mathrm{SiO}_{2}$ composite particles were made up of lumpy masses of irregular shapes and sizes $(25-105 \mathrm{~nm})$. The

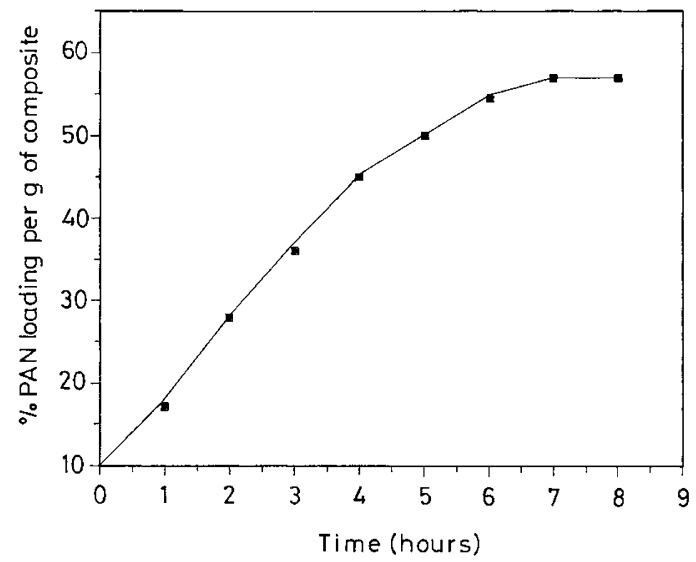

Figure 2. Dependence of $\%$ PAN loading per $g$ of composite on the reaction time; $[\mathrm{AN}]=0.75 \mathrm{~mol} \mathrm{~L}^{-1},\left[\mathrm{~K}_{2} \mathrm{CrO}_{4}\right]=0.06 \mathrm{~mol} \mathrm{~L}^{-1}$, $\left[\mathrm{NaASO}_{2}\right]=0.05 \mathrm{~mol} \mathrm{~L}^{-1}$.

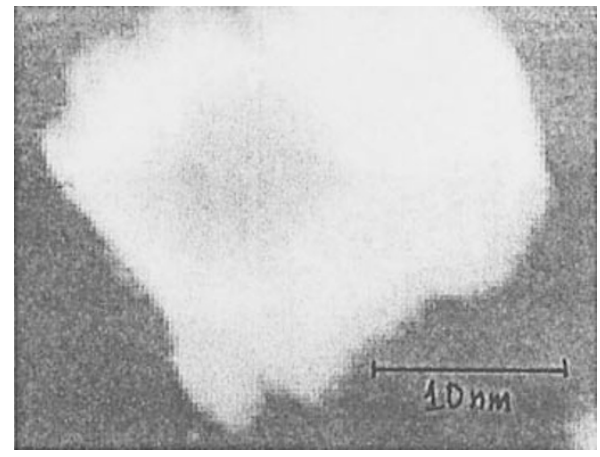

(a)

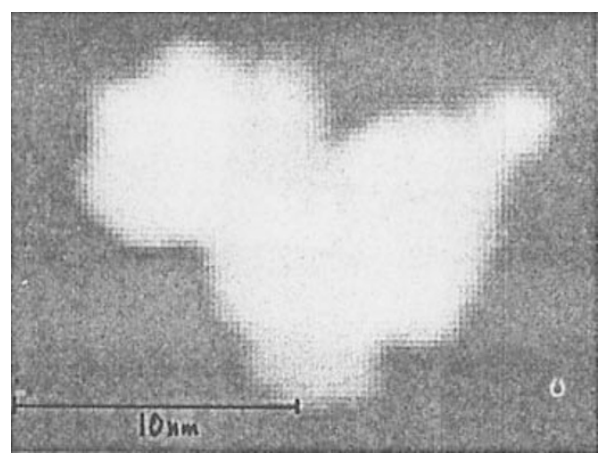

(c) morphology pattern appeared to be similar to the typical 'raspberry' morphology pattern reported by Armes et al. $^{12}$ for PPY-SiO 2 or PANI-SiO 2 nanocomposites and subsequently by Biswas et al. for PNVC-SiO ${ }_{2},{ }^{10}$ PNVC- $\mathrm{Al}_{2} \mathrm{O}_{3},{ }^{6}$ and PTP- $\mathrm{Al}_{2} \mathrm{O}_{3}{ }^{7}$ systems. Such a morphology could develop through aggregation of silica particles glued together ${ }^{13}$ by the precipitating polymer moieties acting as a binder.

\section{Transmission Electron Microscopic Analysis}

TEM analysis of the $\mathrm{SiO}_{2}$ dispersion revealed the presence of stringy particles of average diameter $20 \mathrm{~nm} .{ }^{17}$ The TEM micrograph (Figure 4) of a PAN$\mathrm{SiO}_{2}$ nanocomposite dispersion in the $1000 \mathrm{ppm}$ dilution range clearly indicated the formation of spherical particles with average particle diameter in the 28 $100 \mathrm{~nm}$ range. A similar trend was also observed by Armes et al. ${ }^{17}$ for the PPY, PANI, and $\mathrm{SiO}_{2}$ nanocomposite systems.

\section{Thermogravimetric Stability}

$\mathrm{Wt} \%$ retained versus temperature studies for PAN homopolymer, $\mathrm{PAN}-\mathrm{SiO}_{2}$ nanocomposite and dried $\mathrm{SiO}_{2}$ (Figure 5) revealed the following trend in the order of thermogravimetric stability: dried $\mathrm{SiO}_{2}(12 \%$ weight loss at $\left.799^{\circ} \mathrm{C}\right)>\mathrm{PAN}^{\circ} \mathrm{SiO}_{2}$ nanocomposite $\left(76 \%\right.$ weight loss at $\left.997^{\circ} \mathrm{C}\right)>$ PAN homopolymer

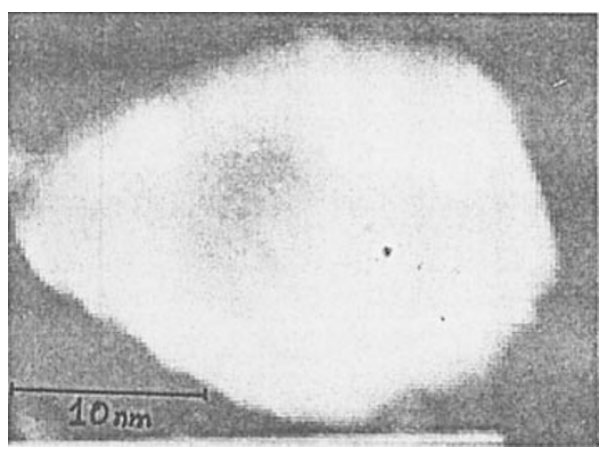

(b)

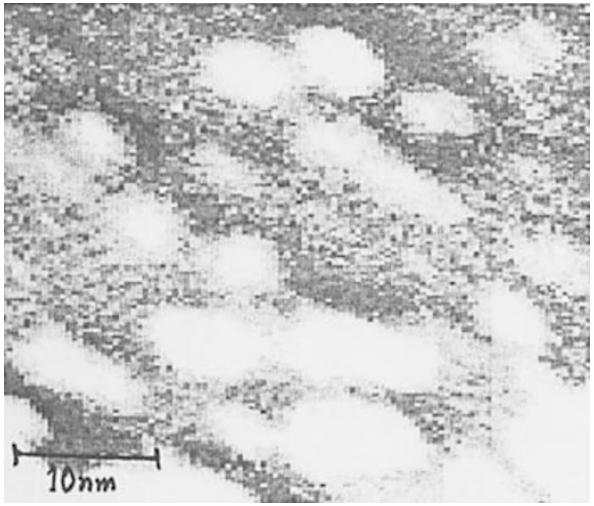

(d)

Figure 3. Scanning electron micrographs of a $\mathrm{PAN}-\mathrm{SiO}_{2}$ composite. 
Table I. D.c conductivities of various PAN-based composites.

\begin{tabular}{|c|c|c|c|}
\hline Entry No & Materials & Conductivity $\left(\mathrm{S} \mathrm{cm}^{-1}\right)$ & Reference \\
\hline 1 & PAN homopolymer & $>10^{-7}-10^{-8}$ & this study \\
\hline 2 & $\mathrm{PAN}_{-} \mathrm{SiO}_{2}$ nanocomposite & $2.1 \times 10^{-6}$ & this study \\
\hline \multirow[t]{2}{*}{3} & PAN-SiO ${ }_{2}$ (Doped with $\mathrm{FeCl}_{3}$ & & \\
\hline & for one week) & $1.2 \times 10^{-5}$ & this study \\
\hline $4^{\mathrm{a}}$ & PANI-(PAN-SiO 2 ) & $3.5 \times 10^{-3}$ & ref 31 \\
\hline $5^{\mathrm{b}}$ & PANI-(PAN-SiO 2 ) & $2.5 \times 10^{-3}$ & ref 31 \\
\hline $6^{\mathrm{a}}$ & PPY-(PAN-SiO $\left.{ }_{2}\right)$ & $2.8 \times 10^{-4}$ & ref 31 \\
\hline $7^{\mathrm{b}}$ & PPY-(PAN-SiO $\left.{ }_{2}\right)$ & $1.5 \times 10^{-4}$ & ref 31 \\
\hline
\end{tabular}

${ }^{\mathrm{a}} \mathrm{ANI} / \mathrm{PY}$ was added to $\mathrm{PAN}-\mathrm{SiO}_{2}$ suspension in aqueous medium to which $\mathrm{FeCl}_{3}$ was added. ${ }^{\mathrm{b}} \mathrm{ANI} / \mathrm{PY}$ was added to $\mathrm{PAN}-\mathrm{SiO}_{2}$ suspension in aqueous medium containing excess $\mathrm{CrO}_{4}=$ in presence of $\mathrm{HCl}$.

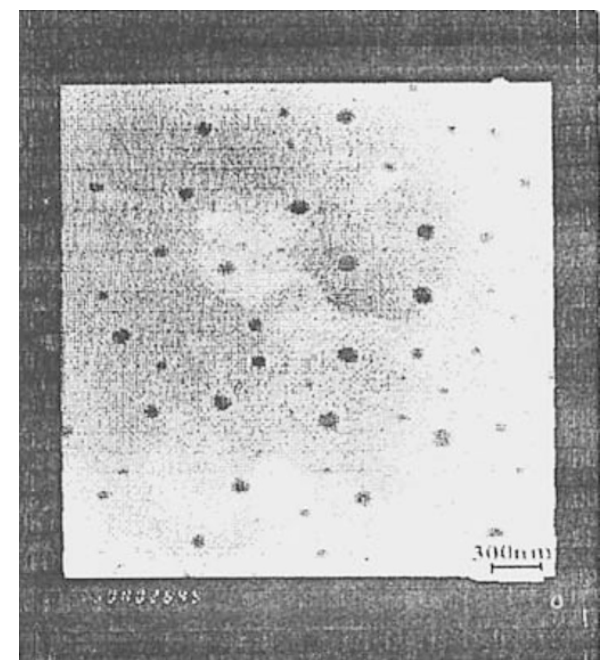

Figure 4. Transmission electron micrograph of a $\mathrm{PAN}-\mathrm{SiO}_{2}$ composite.

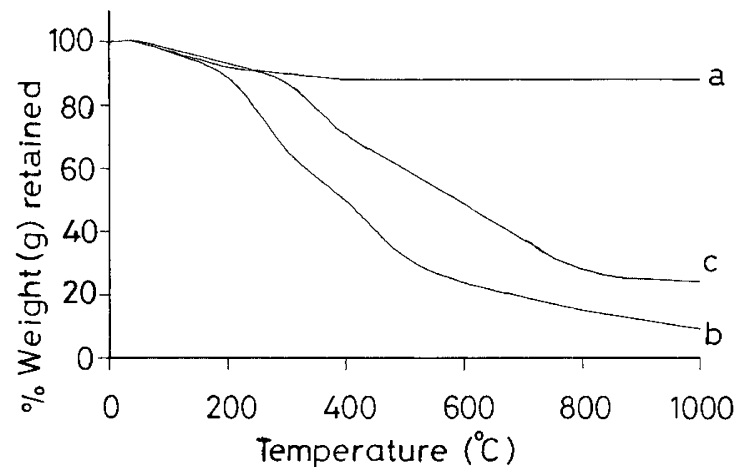

Figure 5. TGA thermograms of (a) Dried Silica (b) PAN homopolymer (c) $\mathrm{PAN}-\mathrm{SiO}_{2}$ nanocomposite.

( $91 \%$ weight loss at $997^{\circ} \mathrm{C}$ ). Such enhancement of thermal stability after polymer-oxide nanocomposite formation was a typical feature of a majority of reported polymer metal oxide composite systems. ${ }^{4-9,12,17}$ This trend could manifest from the formation of a compact polymer- metal oxide nanoaggregates which would require higher thermal energy for degradation.

The DTA scans for both PAN homopolymer and PAN-SiO 2 nanocomposite revealed manifestation of a sharp exothermic peak in the temperature range $487 \pm 20^{\circ} \mathrm{C}$ corresponding to the region of maximum weight loss $\left(300-600^{\circ} \mathrm{C}\right)$. In this range, PAN suffered massive oxidative degradation.

\section{Conductivity Characteristics}

Table I presents the d.c. conductivity values for some PAN-based composites. PAN homopolymer produced in this research did not show any attractive conductivity value. On composite formation with $\mathrm{SiO}_{2}$ somewhat higher conductvity value could be realized in PAN$\mathrm{SiO}_{2}$ systems. External doping with $\mathrm{FeCl}_{3}$ further improved the conductivity $\left(10^{-5} \mathrm{~S} \mathrm{~cm}^{-1}\right)$ as was to be expected.

It occurred to us that an interesting way of improving upon the conductivity of the $\mathrm{PAN}-\mathrm{SiO}_{2}$ composite would be to deposit conducting polymers like PPY or PANI on the preformed $\mathrm{PAN}-\mathrm{SiO}_{2}$ suspension in the aqueous medium. Results of our preliminary experimentations $^{31}$ in this direction (entries 4-7, Table I) were encouraging. Further work is in progress in this direction.

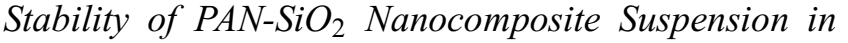 Water}

As mentioned earlier PAN homopolymer separated out as a coagulum in the aqueous medium. However, in presence of nanodimensional $\mathrm{SiO}_{2}$ particles suspended in the aqueous medium the separated PAN particles encapsulated the $\mathrm{SiO}_{2}$ particles and thereby formed the composite which remained suspended in the aqueous medium. This process was widely followed by previous workers ${ }^{4-9,11-24}$ for the preparation of processable dispersions of intractable speciality polymers. The method presented here is expected to be of wide scope since these studies can be extended to miscellaneous water insoluble fundamental polymers including vinyl polymers as well as copolymers of these polymers with the speciality polymers like PPY, PANI, or PTP. 


\section{CONCLUSIONS}

The aqueous polymerization of acrylonitrile was initiated by $\mathrm{CrO}_{4}=/ \mathrm{AsO}_{2}{ }^{-}$redox pair. The same polymerization in presence of nanodimensional $\mathrm{SiO}_{2}$ particulate dispersants in the aqueous medium resulted in the formation of $\mathrm{PAN}_{-} \mathrm{SiO}_{2}$ nanocomposite as a permanently stable suspension. Polymer loading in the composite could be controlled by adjusting $\left[\mathrm{CrO}_{4}{ }^{-}\right] /\left[\mathrm{AsO}_{2}{ }^{-}\right]$. Conductivity of otherwise nonconducting PAN $\left(\sim 10^{-11} \mathrm{~S} \mathrm{~cm}^{-1}\right)$ could be enhanced to $10^{-6} \mathrm{~S} \mathrm{~cm}^{-1}$ through nanocomposite formation with $\mathrm{SiO}_{2}$ and to $\sim 10^{-5} \mathrm{~S} \mathrm{~cm}^{-1}$ by $\mathrm{FeCl}_{3}$ doping.

Acknowledgments. We are grateful to the Council of Scientific and Industrial Research (CSIR), New Delhi, India for funding a project No. 80(0037)/EMRII to MB; the authorities of Presidency college, Calcutta, for facilities; the Director of Central Glass and Ceramic Research Institute, Calcutta, for helpful discussions and measurements of conductivity and to Mr. P. Ray, Saha Institute of Nuclear Physics, Calcutta, for TEM analyses.

\section{REFERENCES}

1. B. H. Kim, J. H. Joo, A. J. Epstein, K. Mizoguchi, J. W. Kim, and H. J. Choi, Macromolecules, 35, 1419 (2002).

2. S. K. Lim, J. W. Kim, I. Chin, Y. K. Kwon, and H. J. Choi, Chem. Mater, 14, 1989 (2002).

3. N. Ballav and M. Biswas, Synt. Met., 132, 213 (2003).

4. S. S. Ray and M. Biswas, Adv. Polym. Sci., 155, 167 (2001).

5. A. Maity and M. Biswas, J. Appl. Polym. Sci., 90, 1058 (2003).

6. N. Ballav and M. Biswas, Polym. Int., 52, 179 (2003).

7. A. Maity and M. Biswas, J. Appl. Polym. Sci., 88, 2233 (2003).
8. S. S. Ray and M. Biswas, Synth. Met., 99, 105 (1999).

9. S. S. Ray and M. Biswas, Synth. Met., 108, 231 (2000).

10. S. S. Ray and M. Biswas, Mater. Res. Bull., 33, 533 (1998).

11. J. Stejskal, P. Kratochvil, S. P. Armes, S. F. Lascelles, A. Riede, M. Helmstedt, J. Prokes, and I. Krivka, Macromolecules, 29, 6814 (1996).

12. S. P. Armes, S. Gottesfeld, J. G. Beery, F. Garzon, and S. F. Agnew, Polymer, 32, 2325 (1992).

13. S. Maeda and S. P. Armes, Synth. Met., 73, 155 (1995).

14. S. Maeda, M. Gill, and S. P. Armes, Chem. Mater, 11, 1959 (1995).

15. P. Tadros, S. P. Armes, and S. K. Luke, J. Mater. Chem., 2, 125 (1992).

16. S. Maeda and S. P. Armes, J. Mater. Chem., 4, 935 (1994).

17. F. Rebecca, J. Jagdeep, M. Shuchi, and S. P. Armes, J. Colloid Interface Sci., 173, 135 (1995).

18. S. Maeda and S. P. Armes, Chem. Mater., 7, 171 (1995).

19. S. Maeda, M. Gill, and S. P. Armes, Langmuir, 11, 1899 (1995).

20. N. Ballav and M. Biswas, Synth. Met., 132, 213 (2003).

21. J. W. Kim, S. G. Kim, H. J. Choi, and M. S. John, Macromol. Rapid. Commun., 14, 1989 (2002).

22. J. W. Kim, S. G. Kim, H. J. Choi, M. S. Suh, M. J. Shin, and M. S. John, Int. J. Mod. Phys. B., 15, 657 (2001).

23. T. H. Kim, L. W. Jang, D. C. Lee, H. J. Choi, and M. S. John, Macromol. Rapid. Commun, 23, 191 (2002).

24. J. W. Kim, M. H. Noh, H. J. Choi, D. C. Lee, and M. S. John, Polymer, 41, 1229 (2000).

25. J. W. Kim, F. Liu, H. J. Choi, S. H. Hong, and J. Joo, Polymer, 44, 289 (2003).

26. K.Ueberreiter and J. Z. Springer, Z. Phys. Chem., 36, 229 (1963).

27. A. Ledwith, P. M. Bower, and D. C. Scherrington, Polymer, 12, 509 (1971).

28. J. G. Bokria and S. Schlick, Polymer, 43, 3239 (2002).

29. Y. Sugahara, S. Satokawa, K. Kuroda, and C. Kato, Clay and Clay Minerals, 36, 343 (1988).

30. N. V. Bhat and E. Sundaresan, J. Appl. Polym. Sci., 42, 1615 (1991).

31. A. Maity and M. Biswas, (2002, Unpublished results). 